American Journal of

\title{
Food Sciences and Nutrition
}

(AJFSN)

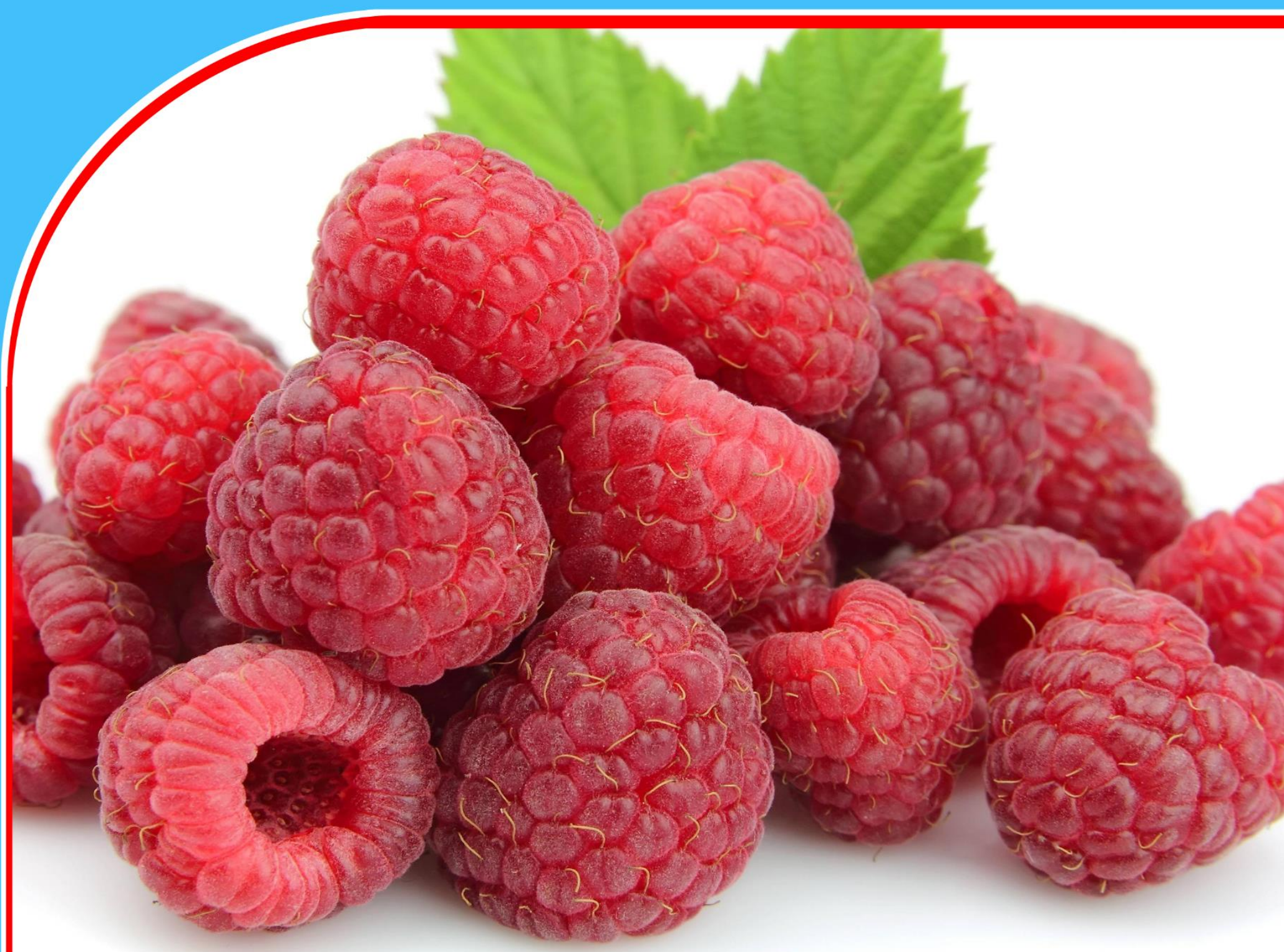

A CROSS SECTIONAL ANALYSIS OF DIETARY PRACTICES AND NUTRITION STATUS OF FEMALE UNDERGRADUATE STUDENTS AT KENYATTA UNIVERSITY, KENYA

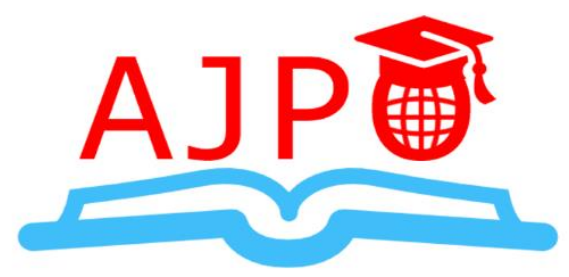

Grace Waweru 


\title{
A CROSS SECTIONAL ANALYSIS OF DIETARY PRACTICES AND NUTRITION STATUS OF FEMALE UNDERGRADUATE STUDENTS AT KENYATTA UNIVERSITY, KENYA
}

\author{
Grace Waweru ${ }^{1}$ \\ School of Health Sciences \\ Gretsa University \\ Corresponding Author's Email: gray.waweru@gmail.com
}

\begin{abstract}
Purpose: This study aimed to establish the dietary practices, assess nutrition status based on body mass index and the relationship between dietary diversity and nutrition status of female undergraduate students at Kenyatta University, Kenya.

Methods: The study adopted a cross-sectional analytical design involving sample of 422 female undergraduate students randomly selected from Kenyatta University. Minimum Dietary Diversity - Women and Food Frequency Questionnaire were used to assess the dietary practices of the female students. Weight and height were measured to assess the nutrition status of the female students. Data obtained was analyzed using Statistical Package for Social Sciences (SPSS) version 22.
\end{abstract}

Results: The results showed that $64.0 \%$ of the participants had consumed $\geq 5$ food groups while $36 \%$ had consumed $<5$ food groups over a period of 24 hours. In terms of nutrition status, $68.4 \%$ of the participants had normal Body Mass Index while $23.9 \%$ were overweight, $5.55 \%$ were underweight and $2.3 \%$ were obese. Minimum Dietary Diversity - Women was significantly associated with nutrition status $(\mathrm{p}=0.044)$.

Recommendation: The results illustrated unhealthy eating habits and sub-optimal nutrition status among a significant number of the female students. Policy makers should scale up interventions that would help improve dietary practices of women of reproductive age particularly university students.

Key words: Dietary practices, Dietary diversity, female students, nutrition status, body mass index 


\subsection{BACKGROUND}

Kenya, like many developing countries has been experiencing rapid changes in dietary habits and lifestyles resulting to the overweight/obesity transition. Students are likely to make poor food choices which may affect their nutrition status during the beginning of college and this may continue throughout their life. ${ }^{[1-2]}$ Young adults' feeding practices have been characterized with frequent snacking, overweight/obesity and skipping of meals particularly breakfast. ${ }^{[1]}$ A study conducted in a Zimbabwe University associated students' poor choices in food with inadequate nutrition knowledge and their failure to understand their nutrition requirements. ${ }^{[3]}$ Another study among female undergraduate students attending various universities in Nairobi revealed that most of the students did not get the recommended daily meals. ${ }^{[4]}$

An individual's nutrition status results from interrelated factors that are influenced by the quantity and quality of food consumed and physical health. Three hundred million women in the world are estimated to be obese making obesity a global health problem. The prevalence is even higher in urban areas where the level of obesity in Kenya is now approaching 50\% among women in urban areas, aged between 19 and 49 years. ${ }^{[5]}$ A study among undergraduate students in Nairobi showed that $22.9 \%$ of the students were overweight and obese while $5.5 \%$ were underweight. ${ }^{[4]}$ Evidence suggests that a young female adult's nutrition status has important effects for her health and the health of her children and is an important factor in breaking the malnutrition cycle. ${ }^{[6]}$

Various studies have demonstrated a positive correlation between good dietary practices and a woman's nutrition status, menstruation, ovulation, the likelihood of conception and pregnancy outcomes. ${ }^{[7-9]}$

The purpose of this study was to determine the dietary practices and nutrition status of female students at Kenyatta University, Kenya

\subsection{Objectives of the Study}

The specific objectives of the study were to:

1. Determine the dietary practices of female students at Kenyatta University, Kenya

2. Assess the nutrition status of female students at Kenyatta University, Kenya

3. Establish the relationship between dietary practices and nutrition status among female students at Kenyatta University, Kenya

\subsection{LITERATURE REVIEW 2.1 Dietary Practices among Female Students}

Over the years, a nutrition transition has been noticed in the developing countries characterized by a change from the traditional diet to westernized diets that are less nutritious and result to undesirable effects on the health status. ${ }^{[10]}$ Several studies have reported a positive relationship between optimal dietary practices and nutrition status. ${ }^{[8-9,11]}$

University Students are likely to make unhealthy food choices which may affect their nutrition status at school and this may continue throughout their life. ${ }^{[1]}$ Students' feeding patterns have 
been associated with unhealthy snacking, overweight and skipping of meals in particular breakfast. ${ }^{[1,3]}$ A study conducted in a University in Zimbabwe reported that students make poor food choices because they fail to understand their dietary requirements and the consequences of unhealthy diets. ${ }^{[3]}$ Another study conducted among university students in Nairobi revealed that most female students failed to achieve their recommended daily intakes. ${ }^{[4]}$

\subsection{Nutrition Status of Female Students}

The nutrition status of individuals results from factors that are influenced by amounts and quality of food intake as well as their health status. Kenya is experiencing the overweight/obesity transition with evidence suggesting a rise in the level of obesity among women in the reproductive age especially in the urban areas. ${ }^{[5,12]}$ According to a study carried out among female university students in Nairobi, the prevalence of overweight and obesity among the students was $22.9 \%$. ${ }^{[4]}$ These are our immediate future mothers and sub-optimal nutrition status increases their risk of poor maternal outcomes. Under nutrition makes a woman weak and reduces her chances of surviving childbirth and giving birth to a healthy baby, which translates to increased maternal and infant morbidity and mortality. Further evidence suggests that obesity increases the risk for gestational diabetes, preterm delivery, cesarean section and giving birth to an overweight child. ${ }^{[13]}$ It is therefore important to emphasize that all women in the reproductive age strive to achieve appropriate weight and optimal nutrient stores that will take care of pregnancy needs during the early stages.

\subsection{METHODOLOGY}

A cross-sectional analytical study design was adopted in the study. The study population included female undergraduate students at Kenyatta University, Kenya. Kenyatta University is a public university in Kenya located 16 kilometers from Nairobi city. The University was chosen purposively as it consist a high number of students with diverse social, economic and cultural backgrounds. A total of 422 students were selected to participate in the study but 32 had incomplete questionnaires hence the final analysis included 390 students.

\subsection{Data Collection and Statistical Analysis}

Data was collected using a researcher administered questionnaire. A Minimum Dietary Diversity - Women (MDD-W) was used to assess dietary practices. ${ }^{[14]}$ More information on dietary practices was collected using a 7-day Food Frequency Questionnaire (FFQ). ${ }^{[4,14]}$ Weight was taken using a salter scale and height using a stadiometer. Data obtained was analyzed using Statistical Package for Social Sciences (SPSS) version 22. Descriptive statistics like mean, standard deviations and percentages were used to describe the study population. To determine the MDDS of the students, a point was awarded to each food group consumed over the reference period and a sum computed for all points. Adequate consumption was based on consumption of five or more food groups. ${ }^{[14]}$ Body Mass Index (BMI) was used to assess nutrition status. The BMI was classified as either underweight $\left(<18.5 \mathrm{~kg} / \mathrm{M}^{2}\right)$, normal $\left(18.5-24.9 \mathrm{Kg} / \mathrm{M}^{2}\right)$, overweight $\left(25.0-29.9 \mathrm{Kg} / \mathrm{M}^{2}\right)$ and obese $\left(>30.0 \mathrm{Kg} / \mathrm{M}^{2}\right) .{ }^{[15]}$ 
Chi-square test was used to establish relationship between dietary practices and nutrition status. In all the analyses, a $\mathrm{P}$ value of $<0.05$ was considered significant.

\subsection{Ethics Consideration}

Approval to conduct the research was sought from Kenyatta University graduate school and ethical clearance obtained from Ethical Review Committee of Kenyatta University. A research permit was obtained from the National Council for Science Technology and Innovation (NACOSTI). Permission was also sought from the Kenyatta University administration. Participation was voluntary through informed written consent from the respondents. Confidentiality and privacy of the data collected was assured and maintained during and after the study.

\subsection{RESULTS}

\subsection{Dietary Practices among Female Students}

\subsubsection{Minimum Dietary Diversity Score of the Female Students}

The mean MDDS was 5.11 \pm 1.66 with a minimum score of 0 and a maximum score of 10 food groups. More than half of the respondents $(64 \%)$ had consumed $\geq 5$ food groups while $36 \%$ had consumed $<5$ food groups (Figure 1).

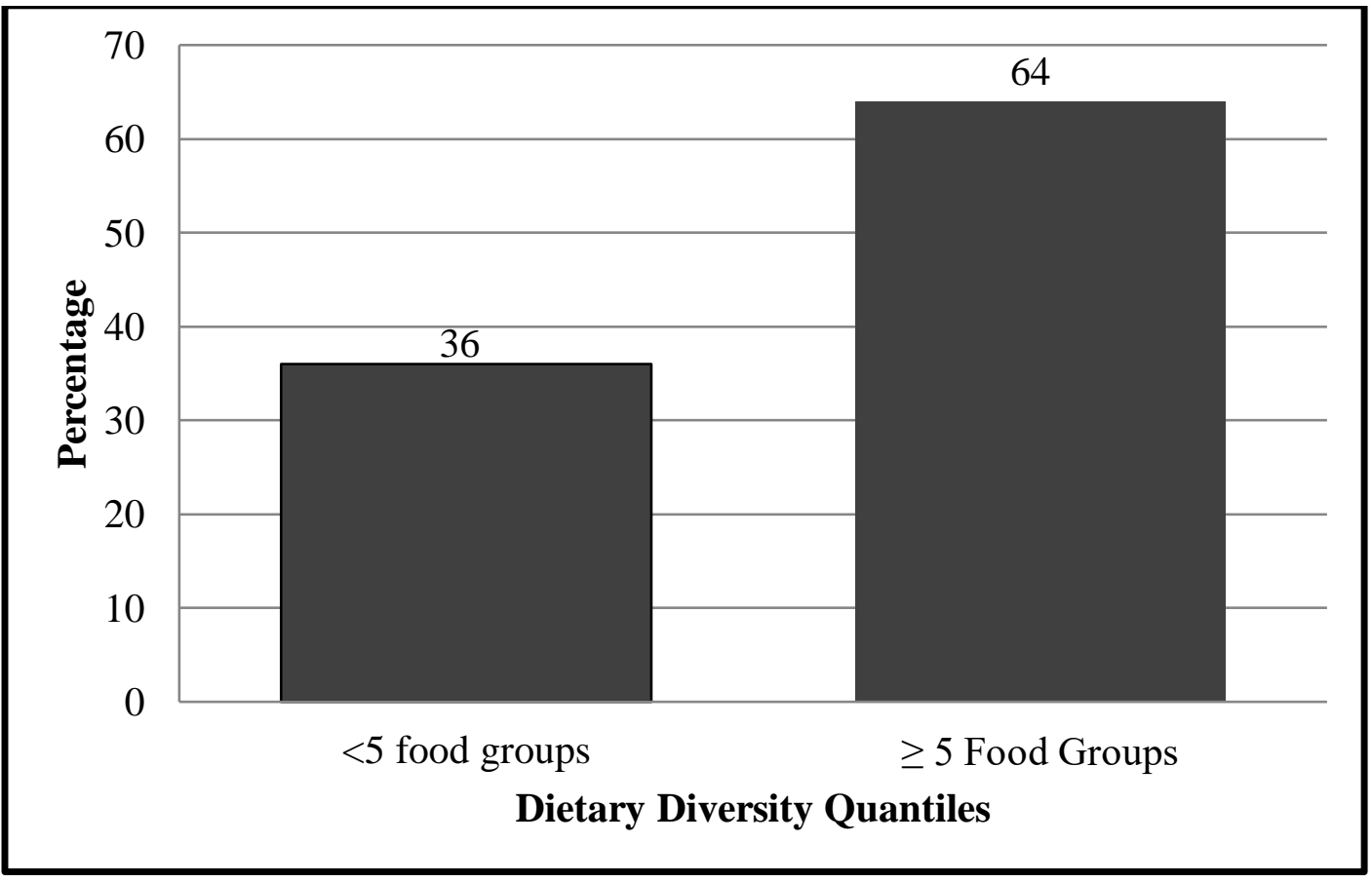

Figure 1: Respondents minimum dietary diversity scores

\subsubsection{Consumption of Foods by Participants based on Food Groups}


Generally, the food group that was mostly consumed by the female students was cereals and other vegetables at $92 \%$ and $78.4 \%$ respectively. Nuts and seeds were the least consumed at $18.4 \%$ (Figure 2).

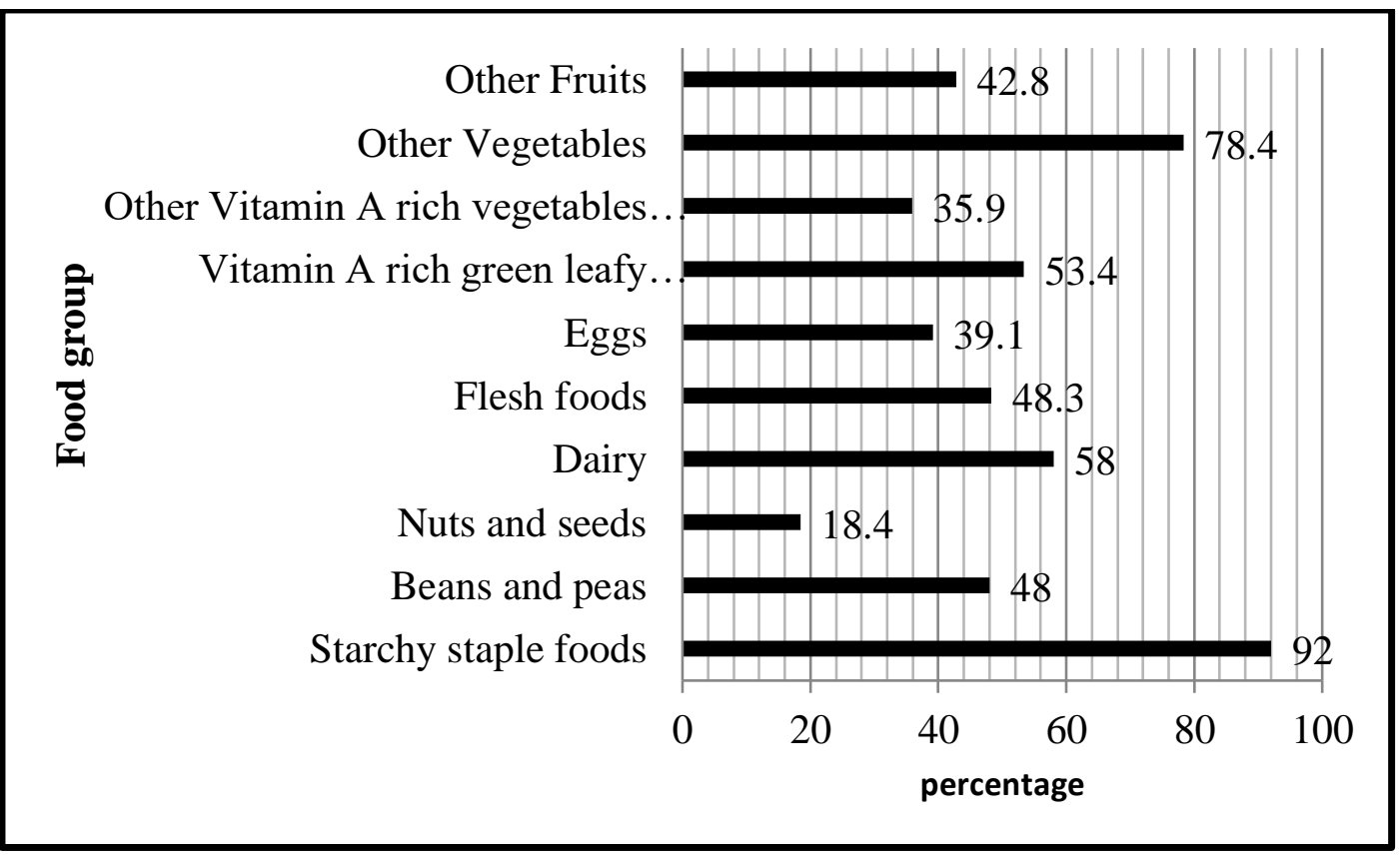

Figure 2: Consumption of foods by participants based on food groups

\subsubsection{Frequency of Consumption of Various Food Groups among the Respondents}

The food group most frequently consumed was cereals and cereal products with $59.5 \%$ of the respondents consuming daily. Milk and milk products were consumed everyday by $24.7 \%$. Only $11.8 \%$ of the students consumed meat, poultry and their products every day and while $2.9 \%$ never consumed. Fruit and vegetables were consumed everyday by $38.5 \%$ and $47.1 \%$ of the students, respectively. Beverages were consumed by $45.4 \%$ of the students every day (Table 1)

Table 1: Frequency of food consumption

\begin{tabular}{lllll}
\hline \multirow{2}{*}{ Food type } & \multicolumn{4}{l}{ Frequency per week } \\
\cline { 2 - 5 } & Everyday & $\begin{array}{l}\mathbf{1 - 2} \text { times } \\
\text { a week } \\
(\boldsymbol{\%})\end{array}$ & $\begin{array}{l}\mathbf{3 - 6} \text { times } \\
\text { a week } \\
(\boldsymbol{\%})\end{array}$ & $\begin{array}{l}\text { Never } \\
\text { consumed } \\
(\boldsymbol{\%})\end{array}$ \\
\hline Cereals and cereal products & 59.5 & 17.8 & 22.7 & - \\
Roots and tubers & 4.9 & 62.4 & 16.4 & 16.4
\end{tabular}




\begin{tabular}{|c|c|c|c|c|}
\hline Milk and milk products & 24.7 & 45.7 & 19.8 & 9.8 \\
\hline Meat, poultry \& products & 11.8 & 58.0 & 27.3 & 2.9 \\
\hline Legumes and nuts & 25.9 & 46.6 & 21.3 & 6.3 \\
\hline Fruits & 38.5 & 35.9 & 25.0 & 0.6 \\
\hline Vegetables & 47.1 & 29.9 & 19.8 & 3.2 \\
\hline Sweets & 34.5 & 34.2 & 19.5 & 11.8 \\
\hline $\begin{array}{l}\text { Beverage; soft drinks, fresh } \\
\text { juice, Fresh squash, tea, cocoa }\end{array}$ & 45.4 & 31.3 & 17.2 & 6.0 \\
\hline $\begin{array}{l}\text { Others; Sausages, Smokies, } \\
\text { Hotdogs, pizza }\end{array}$ & 9.5 & 50.9 & 19.8 & 19.8 \\
\hline
\end{tabular}

\subsection{Nutrition status of the respondents}

The mean height of the respondents was $160.3 \pm 6.5 \mathrm{SD} \mathrm{cm}$. The lowest height was $139 \mathrm{~cm}$ while the highest height was $179 \mathrm{~cm}$. The mean weight was $58.7 \pm 9.3 \mathrm{SD} \mathrm{kg}$ with the lowest and highest weight being $36 \mathrm{~kg}$ and $88 \mathrm{~kg}$, respectively. The mean BMI was $23 \pm 3.1 \mathrm{SD}$ with a low of $15 \mathrm{~kg} / \mathrm{m}^{2}$ and a high of $34.9 \mathrm{~kg} / \mathrm{m}^{2}$. Generally, $68.4 \%$ of the respondents had normal BMI while $23.9 \%$ were overweight, $5.55 \%$ were underweight and $2.3 \%$ were obese (Figure 2).

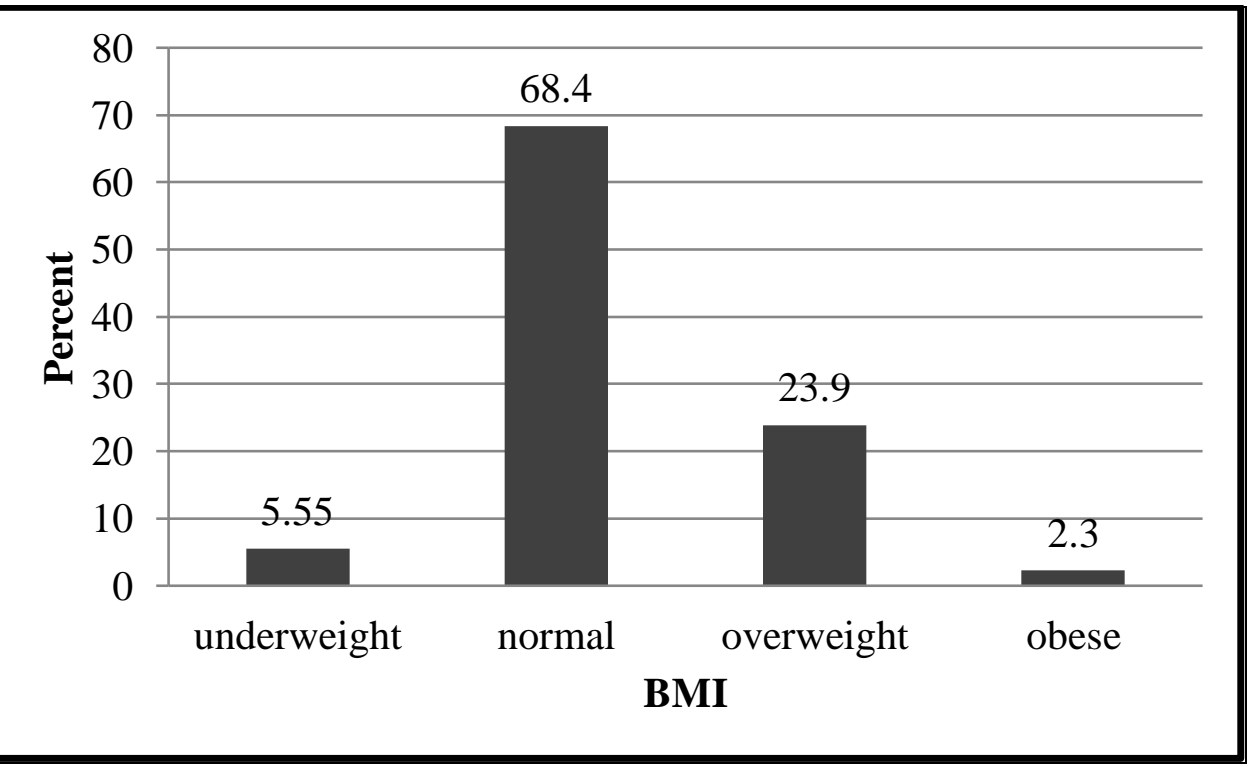

Figure 3: Respondents nutrition status 


\subsection{Relationship between minimum dietary diversity-women and nutrition status}

Table 2 shows results of chi-square test between MDDS-W and nutrition status. The test revealed a significant relationship between dietary diversity-women and nutrition status of the respondents $\left(\chi^{2}=7.214\right.$, df $\left.=1, \mathrm{p}=0.044\right)$.

Table 2: Relationship between minimum dietary diversity- women and nutrition status

\begin{tabular}{lll}
\hline Variable & $\mathbf{N}=390$ & \\
\cline { 2 - 3 } MDDS-W vs. & $\chi^{2}$ & P value \\
\hline Knowledge of the respondent & 7.214 & $0.044^{*}$ \\
\hline
\end{tabular}

* Significance at $\mathrm{p}<0.05$

\subsection{DISCUSSION}

The young population in university contributes to the poor eating habits among university students. ${ }^{[4,16-17]}$ Junk food makes up the main meals for most young people in urban and periurban centres.

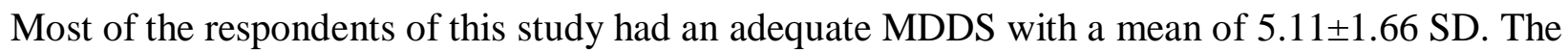
results compare with previous studies. ${ }^{[18-19]}$ However, these previous studies considered a total of 13 and 8 food groups, respectively in contrast to this study which considered 10 food groups. The higher dietary diversity could be attributed to the affordability of meals in the University's cafeterias and the nearby market where most of the students get their meals from. The low consumption of nuts and seeds observed among the respondents could be as a result of financial constraints.

From the 7 day food frequency, several undesirable food habits were observed among the respondents in this study including consumption of sweets with about $88.8 \%$ of the students consuming at least once in a week, intake of beverages with $45.4 \%$ of the students consuming every day and foods like sausages, smokies and hotdogs being consumed by $50.9 \%$ of the respondents every day. Excess intake of these foods has been associated with diabetes, overweight, obesity and cardiovascular diseases. ${ }^{[10]}$ Similar results were reported in a previous study among undergraduates in South West Nigeria where they reported low intake of meat and meat products. ${ }^{[19]}$ Poor food choices among university students were also reported in other studies. ${ }^{[1,3-4]}$ The frequent consumption of these unhealthy foods could be attributed to the ease in access of these foods in the university's cafeterias, tuck shops and a nearby local market. An additional contributing factor could be as a result of a clash between class times and meals which interferes with normal meal patterns. The low consumption of fruits and vegetables could be attributed to costs and their seasonality.

Majority of the students in this study had normal nutrition status (68.4\%). The relatively high level of overweight reported among the respondents could be attributed to high intake of unhealthy foods like sausages, hot dogs, sweets and beverages as witnessed in the study. 
Various forms of malnutrition have been associated with women's dietary practices. Overweight and Obesity may predispose women to non-communicable diseases like coronary heart disease, diabetes mellitus, stroke and various forms of cancers. ${ }^{[10]}$ The consequence of overweight and obesity among young women is critical not only during pregnancy but also during the preconception period. The study results showed that underweight was significantly higher among students who had lower MDDS-W while Overweight was found to be higher among those who did not frequently consume fruits and vegetables. The findings of this study compares with a previous study that reported that overweight was more prevalent among adolescents who consumed inadequate amounts of fruits and vegetables. ${ }^{[20]}$ Fruits and vegetables contain fibers that help with digestion and weight control.

\subsection{CONCLUSION}

Findings of this study demonstrated high frequency of intake of low nutritious foods like soft drinks, sausages, hotdogs and sweets. The results illustrated a significant number of female students had sub optimal nutrition status. Proper dietary practices ensure female students meet their nutrition requirements for optimum nutrition status and reduce their risk of poor maternal health. Nutrition status had a significant relationship with dietary practices. Policy makers in the ministry of health and education should scale up intervention programs aimed at improving dietary practices among women of reproductive age. University eating premises should also find ways of ensuring that the food and meals available are nutritious, varied, convenient, acceptable and affordable. This would ensure that students are discouraged from relying on unhealthy and convenient fast foods that expose them to poor nutrition status.

\section{REFERENCES}

1. Isa, K. A. M., \& Masuri, M. G. (2011). The association of breakfast consumption habit, snacking behavior and body mass index among university students. American Journal of Food and Nutrition, 1(2), 55-60.

2. Soriano, J. M., Moltó, J. C., \& Manes, J. (2000). Dietary intake and food pattern among university students. Nutrition Research, 20(9), 1249-1258.

3. Manwa, L. (2013). University Students' Dietary Patterns: A Case of a University in Zimbabwe. Journal of Emerging Trends in Educational Research and Policy Studies, 4(1), 191.

4. Kinyua, L. W. (2013). Association of Nutrition Knowledge and Attitude With Dietary Practices And Nutrition Status Of Female Undergraduate Students Attending University Colleges Within Nairobi Metropolis (Doctoral dissertation, University of Nairobi).

5. Haddad, L. J., Hawkes, C., Achadi, E., Ahuja, A., Ag Bendech, M., Bhatia, K., \&

6. Fanzo, J. (2015). Global Nutrition Report 2015: Actions and accountability to advance nutrition and sustainable development. Intl Food Policy Res Inst.

7. Leese, H. (2014). Effective nutrition from conception to adulthood. Human Fertility, $17(4), 252-256$.

8. Dean, S. V., Lassi, Z. S., Imam, A. M., \& Bhutta, Z. A. (2014). Preconception care: nutrition risks and interventions. Reproductive health, 11(3), 1. 
9. Grieger, J., Grzeskowiak, L., \& Clifton, V. (2014). Pre-conception Dietary Patterns in Human Pregnancies Are Associated with Preterm Delivery. Journal of Nutrition, 144(7), 1075-1080.

10. Bonaccio, M., Iacoviello, L., de Gaetano, G., \& Moli-Sani Investigators. (2012). The Mediterranean diet: the reasons for a success. Thrombosis research, 129(3), 401-404.

11. Zimmermann, M. (2012). The Effects of Iodine Deficiency in Pregnancy and Infancy. Paediatric and Perinatal Epidemiology, 26(s1), 108-117.

12. Ettarh, R., Van de Vijver, S., Oti, S., \& Kyobutungi, C. (2013). Overweight, Obesity, and Perception of Body Image Among Slum Residents in Nairobi, Kenya, 2008-2009. Preventing Chronic Disease, 10(2), 34-36.

13. Insel, P. (2016). Nutrition. Sudbury: Jones \& Bartlett Learning.

14. FAO.(2018) Dietary Assessment: A resource guide to method selection and application in low resource settings. Rome.

15. WHO. (2008).Body Mass Index- BMI. Retrieved_from http://www.euro.who.int/en/health-topics/disease-prevention/nutrition/a-healthylifestyle/body-mass-index-bmi

16. Shill, K. B., Karmakar, P., Kibria, M. G., Das, A., Rahman, M. A., Hossain, M. S., \& Sattar, M. M. (2014). Prevalence of iron-deficiency anaemia among university students in Noakhali region, Bangladesh. Journal of health, population, and nutrition, 32(1), 103.

17. Garcia, A. C., Sykes, L., Matthews, J., Martin, N., \& Leipert, B. (2010). Perceived facilitators of and barriers to healthful eating among university students. Canadian Journal of Dietetic Practice and Research, 71(2), e28-e33.

18. Mehlawat, U. (2015). Dietary diversity score of college going students (17-21 years) and its association with family income in India. The Indian Journal of Nutrition and Dietetics, 52(3), 277-285.

19. Sedodo, N. S., Akinlotan, J. V., Akinlua, O., Abosede, O. P., \& Isaac, O. S. (2014). Dietary diversity score and nutrition status of undergraduates in South West Nigeria. $J$ Obes Wt Loss Ther $S, 4,2$.

20. Otuneye, A. T., Ahmed, P. A., Abdulkarim, A. A., Aluko, O. O., \& Shatima, D. R. (2017). Relationship between dietary habits and nutrition status among adolescents in Abuja municipal area council of Nigeria. Nigerian Journal of Paediatrics, 44(3), 128135. 